\title{
Curved Drilling via Inner Hole Laser Reflection
}

\author{
Abbreviated title: Curved Drilling by a Reflected Laser
}

\author{
Hirofumi Hidai", Yousuke Kuroki, Souta Matsusaka, Akira Chiba and Noboru \\ Morita \\ Department of Mechanical Engineering, Chiba University, Chiba, Japan \\ *Corresponding author. Email: hidai@faculty.chiba-u.jp
}

\section{Abstract}

In this paper, we describe curved hole drilling via the reflection of a laser beam off the sidewall of the drilled hole. A slightly offset laser beam forms a tilted surface at the bottom of the hole, controlling the angle of curvature. An ultraviolet laser beam operating at a wavelength of $266 \mathrm{~nm}$ was used. To visualize the hole formation process, borosilicate glass was used as the laser workpiece. This method was able to drill a curved hole with an average angle of $\sim 3^{\circ}$ with curvature beginning at a depth of $400-600 \mu \mathrm{m}$. A curved hole with a diameter of $<50 \mu \mathrm{m}$ was achieved. A branched hole was also demonstrated by using the reflection of the tilted sidewall. The curved hole formation process was recorded with a high speed camera. Once the ablated sidewall reached a certain depth, drilling ceased as the laser energy fell below the ablation threshold. Ultimately, judicious selection of an appropriate laser fluence and sidewall angle allow the formation of curved holes.

Keywords: curved hole, laser drilling, borosilicate glass, high-aspect-ratio hole 


\section{Introduction}

Curved hole drilling has been the focus of much investigation because it increases flexibility in mechanical design. For example, electrical discharge machining has been used to drill curved holes by attaching an electrode to the tip of a universal joint or self-moving electrode [1]. An electrochemical machining technique was tested by placing an electrode on the tip of a flexible tube [2]. Laser drilling has been performed by emitting a laser beam and liquid jet from the tip of a thin curved tube [3].Optical fiber has also been used to transmit laser light to the bottom of a curved hole $[4,5]$. When drilling into a transparent material, a laser beam can be focused within the material. Many investigations have reported curved hole formation in glass with ultra-short pulsed lasers by direct ablation [6] or modification and successive chemical etching [7].

To date there have been various reports on deep laser drilling. Forsman et al. [8] reported that a double laser pulse with a delay of $30-150$ ns was an effective means of deep drilling. Tokarev et al. calculated final hole profile and depth vs. incident fluence and achieved high aspect ratio holes $[9,10]$. Ancona et al. [11] demonstrated that a heat accumulation effect enhanced ablation rate. Döring et al. [12] demonstrated that a reduced ambient pressure lead to an increased ablation rate and therefore drilling efficiency. Unwanted hole bending during laser drilling has also been previously investigated. Kononenko et al. [13] showed that bending was caused by the structural anisotropy and Fresnel reflection coefficient on polarization orientation. Döring et al. [14] drilled a silicon wafer with a femtosecond laser and attributed the curved hole formation to the intensity distribution at the bottom of the hole. Xia et al. [15] concluded that the disturbance of the laser beam by the ablated aerosol caused bending.

We have previously investigated deep micro drilling in glass using ultraviolet lasers [16-18]. In these experiments, the inner surface reflection of the hole enables deep drilling. Additionally, it was shown that the laser energy emitted through the hole was larger than 
the calculated energy without including the effect of surface reflection [16]. In the work described herein, we demonstrate curved hole drilling by using the reflection of a laser beam at the bottom of the hole with an ultraviolet laser. The tilted side wall at the hole bottom was formed by the slight offset of the laser beam, thereby controlling curve direction. Borosilicate glass was used to visualize the hole formation process.

\section{Experimental}

The experimental apparatus used for the present work was same as that described in our previous reports [19]. Briefly, a circularly polarized ultraviolet laser beam (DS20H-266, Photonics Industries International, Inc., NY, USA) was focused on the sample through a convex lens with a focal length of $30 \mathrm{~mm}$. The laser was operated with a wavelength of 266 $\mathrm{nm}, 100 \mu \mathrm{J}$ of energy, a repetition rate of $10 \mathrm{kHz}$ and pulse width of $8 \mathrm{~ns}$. The calculated beam spot diameter was $14.5 \mu \mathrm{m}$. The laser beam was $\mathrm{TEM}_{00}$ mode and beam quality factor $\mathrm{M}^{2}$ was $<1.3$. The beam divergence was $<1 \mathrm{mrad}$. Borosilicate glass $\left(\right.$ Pyrex ${ }^{\circledR}$, Corning 7440, Corning Inc., NY, USA) with a thickness of $10 \mathrm{~mm}$ was used as the workpiece. The laser was focused on the top surface of the glass. A high-speed camera (phantom v7.3, Vison Research Inc., NJ, USA) was set orthogonal to the optical axis of the laser beam to observe the drilled hole. The shutter of the high-speed camera and the timing of the laser pulse were synchronized using a delay generator. The camera exposure time was set to $30 \mu \mathrm{s}$. A transmitted image was obtained by placing a light source on the back face of the sample.

The possibility of curved hole formation was first confirmed by drilling a deep hole. The deep hole was formed by using 5000 laser pulse illuminations without sample movement. After 5000 laser pulse illuminations, the drilled hole was observed by the camera and the sample was moved $2 \mu \mathrm{m}$ in the orthogonal direction of the laser optical axis. Then, another 5000 laser pulses were illuminated. In this study, a cycle comprises the 
following processes: laser illumination, observation by the camera, and sample movement. Thus, the laser was illuminated for 5000 pulses, the hole image was obtained, and the sample was moved, followed by the next cycle. In this paper, the number of cycles is expressed as $N$, the number of laser pulses in the $N$-th cycle is $P_{N}$, the sample movement in the $N$-th cycle is $\Delta x_{N}$, and the position of the laser illuminated during the $N$-th cycle is $X_{N}$. The position where the image is obtained during the $N$-th cycle is indicated by

$$
X_{N}=\sum_{n=1}^{N-1} \Delta x_{n}
$$

Curved hole drilling was then attempted after pilot hole drilling by changing laser illumination conditions: total number of cycles, $N$; number of pulses in the $N$-th cycle, $P_{N}$; and sample shift in the $N$-th cycle, $\Delta x_{N}$. The number of laser pulses in the last cycle, adjusted to the total number of pulses, was 5000 (except for blanched hole formation). The following equation is therefore derived:

$$
\sum_{n=1}^{N-1} P_{n}+P_{N}=5000
$$

\section{Results}

\subsection{Hole drilling with sample shift}

A deep hole was formed by using 5000 laser pulse illuminations without relative offset of the laser beam. The number of pulses and illuminated positions are listed in Table 1. Results are shown in Fig. 1. In the first cycle, a straight hole was formed as indicated by an arrow in Fig. 1. The top of the hole became slightly thicker by the fourth cycle. At the fifth cycle, the hole drilled into the right side of the previous hole as indicated with an arrow even though the laser was illuminating the left side of the previous hole. In the seventh and eighth cycles, the holes were formed on the right side of previous hole. By the $32^{\text {nd }}$ cycle, the hole started to curve at a depth of $\sim 600 \mu \mathrm{m}$ as indicated by an arrow and the bottom of the hole began to be drilled in a tangential direction. At the $33^{\text {rd }}$ cycle, a straight hole was 
formed on the left side of the previous hole as shown by an arrow. The hole did not follow the curved part and branched at a depth of $\sim 650 \mu \mathrm{m}$. The same phenomena occurred, as indicated by an arrow, at the $43^{\text {rd }}$ cycle. Note that, in this paper, the hole that formed at the separated bottom is called a blanched hole. A blanched hole formed when the new hole did not follow the previous hole. The hole that was not matched with the laser beam direction is referred to as a curved hole.

The sidewall of the hole curved and the deeper part of the hole was drilled in a tangential direction as the number of cycles increased. After a certain number of cycles, a straight hole was formed that did not follow the sidewall. The laser energy decayed in the deep area of the hole, and the sidewall ablated because the laser beam illuminated an area with a larger angle of incidence. Therefore, the laser beam was reflected, and a curved hole was formed. After a sufficient number of cycles, the curved area close to the surface (and larger laser energy) and titled angle became large (incident angle became small) so the curved area was ablated and a straight hole was formed as shown in the $33^{\text {rd }}$ cycle and the $43^{\text {rd }}$ cycle. Based on this result, a pilot hole was drilled to a depth of $\sim 600 \mu \mathrm{m}$ with a tilted sidewall at the hole bottom. Further laser illumination formed a curved hole.

\subsection{Curved hole formation}

Curved hole drilling was attempted using the following conditions: the number of cycles $N$ was 11 , the sample shift in a cycle $\Delta x_{N}$ was $2 \mu \mathrm{m}$ and $P_{N}(N=1-10)$ was varied every 20 pulses. Typical results are shown in Fig. 2. Tables $2-4$ show the relationship between the illuminated pulse and illuminated position of the typical result (shown in Fig. $2)$. For reference, the result without any sample shift $\left(\Delta x_{N}=0, P_{N}=100(N=1-10)\right)$ is shown in Fig. 2(d). No difference was observed in the size of the hole around the entrance when the beam was shifted, because the total sample movement was the same. A straight hole except around the bottom the hole was drilled under the conditions described in Table 
2 (Fig. 2(a)) and slight curve was observed at the bottom of the hole. Unintended curve was formed up to $300 \mu \mathrm{m}$ from the bottom of the hole. The unintended curve had no regularity and was caused by disturbance of the laser beam by the ablated material in the hole [15]. We did not discuss unintended curve around the bottom but intended curved hole by sample move. A curved hole was formed under the conditions described in Table 3 as shown in Fig. 2(b), and the hole was curved at the hole bottom by the tenth cycle (at depth of $\sim 450 \mu \mathrm{m}$ ). The diameter of the entrance of the hole was $\sim 50 \mu \mathrm{m}$. The diameter became thinner as depth increased, and was less than $10 \mu \mathrm{m}$ as shown in Fig.2. (e)-(g). The diameter was almost constant in the area deeper than where curvature began $(\sim 450 \mu \mathrm{m})$. Modifications observed around the hole were considered to be thermal damage. Under the conditions described in Table 4 (Fig. 2(c)), a straight hole was obtained, and the hole began to branch by the eleventh cycle. Most of the drilled holes were straight where $P_{N}(N=1-10)$ was 40 . Holes, however, were branched or straight when $P_{N}(N=1-10)$ was 160 . A curved hole was formed when $P_{N}(N=1-10)$ was 60-140. Five holes were drilled under the same conditions, and the curve angle and depth were measured. As shown in Fig. 3(a), two tangential lines were drawn at the center of the upper section and the lower section, respectively. The curve angle $\varphi$ was defined as the angle formed by these two lines and the depth of their intersection was defined as the curve depth. Curve angle and depth are plotted in Fig. 3. The curve angle was at most $\sim 6^{\circ}$, and $\sim 3^{\circ}$ on average. The region of curvature was located at a depth of 400-600 $\mu \mathrm{m}$.

The total number of cycles, $N$, was then varied. $P_{N}$ was set to 100 pulses and $\Delta x_{N}$ was $2 \mu \mathrm{m}$. As shown in Fig. 4, a straight hole was drilled when the total shift $\left|X_{N}\right|$ was 12 $\mu \mathrm{m}$ and $N$ was 7 . When the total shift $\left|X_{N}\right|$ was $32 \mu \mathrm{m}$ and $N$ was 17 , the hole formed in the last cycle did not follow the hole formed in previous cycle. The number of pulses and illuminated position is listed in table 5 for the case when the total shift $\left|X_{N}\right|$ was $32 \mu \mathrm{m}$ and 
$N$ was 17 (Fig. 4(b)). The curve angle and curve depth were measured in the same manner

as Fig. 3 and the results are shown in Fig. 5. Note that the sample was shifted in the opposite direction so the total shift was negative. In most cases, when the total shift $\left|X_{N}\right|$ was $12 \mu \mathrm{m}$ or $32 \mu \mathrm{m}$ and $N$ was 7 or 17 , respectively, a straight hole was formed. Figure 5 displays the results when the total shift $\left|X_{N}\right|$ was $16-28 \mu \mathrm{m}$ and $N$ is $9-15$. The curve angle was $\sim 3^{\circ}$ on average. No clear difference in the shift direction was observed therefore the curved region did not form as a result of the heterogeneous beam profile. The curve depth was located at 400-600 $\mu \mathrm{m}$ and the result shown is similar to Fig. 3(c). The curved hole in the opposite direction is shown in Fig. 6 and the conditions are shown in table 3. The straight hole in the center was the reference hole, which was drilled without a shift $\left(\Delta x_{N}=0\right.$ $\mu \mathrm{m})$.

\subsection{In situ observation and curved hole formation process}

The curved hole formation process was recorded using a high speed camera under the conditions shown in table 3 . The camera and the laser were synchronized and images of the hole were taken when the laser was not illuminated. The result is shown in Fig. 7 and supplemental movie 1 . The depth of the hole was $\sim 550 \mu \mathrm{m}$ after 1000 pulse illuminations. The hole did not become deeper but became thicker during pulses 1000-1300. After the $1150^{\text {th }}$ pulse, slight bulges were observed on the left sidewall (as indicated by a red arrow), and on the right sidewall (as indicated by a blue arrow). These bulges moved downward with an increasing number of pulses (shown during 11-13s in Movie 1). These bulges on

the sidewall of the hole were laser ablated part. After the $1400^{\text {th }}$ pulse, the movement of the bulge on left side stopped and the hole became deeper with increasing number of laser pulses. This bulge formed a curved region. In order to easily identify the movement of the bulge, the hole profiles after pulse numbers 1200, 1300, and 1400 are plotted in Fig. 7 (b). The bulge after pulse 1200 is indicated by arrows. The bulge moves downward at pulse 
1300. After the $1400^{\text {th }}$ pulse, the ablation on the left hand side ceases and only the right hand side is ablated. For reference, the hole formation is observed without sample movement as shown in Fig. 8. The hole becomes deeper with an increasing number of pulses and therefore the drilling progresses continuously.

An illustration of the mechanism driving the curved hole formation is shown in Fig. 9. Laser illumination is shifted from the position of the previously formed hole (Fig. 9(a)), and therefore ablates the sidewall of the hole. The laser fluence is high enough to ablate the sidewall when the ablated position is close to the hole entrance and therefore the hole is drilled along the beam axis (Fig. 9(b)). At the same time, the bottom of the hole is tilted. The bottom is tilted because the laser exhibits a Gaussian beam, therefore the center of the hole was ablated faster than periphery of the hole. The sample movement $(2 \mu \mathrm{m})$ was smaller than beam spot radius $(7.25 \mu \mathrm{m})$. The reflected laser therefore ablates the opposite side of the wall.

Once the ablated sidewall reaches a certain depth, ablation ceases because the laser energy falls below the ablation threshold (Fig. 9(c)). However, ablation at the opposite side continues and a curved hole is formed (Fig. 9(d)). The reason for the ablation threshold difference between the left and right side is explained by the incidence angle as shown in Fig. 9(e). When the sidewall is tilted by $\theta$, the incidence angle at the tilted wall (right side of Fig. $9(\mathrm{e})(90-\theta))$ is larger than that at the left side $(90-2 \theta)$. Here, it is assumed that the right sidewall and the optical axis are parallel. Hence, the laser fluence is larger on the right side than that of the left side. This difference enables the curved hole formation.

In the case that a tilted sidewall was formed at a depth between $400 \mu \mathrm{m}$ and $600 \mu \mathrm{m}$, the direction of the laser beam propagation was changed by reflection and a curved hole is formed. In the case when a curved tilted sidewall forms at a depth of less than $400 \mu \mathrm{m}$, a straight hole is formed because of the laser fluence, which is high enough to ablate the sidewall. For a tilted sidewall that was deeper than $600 \mu \mathrm{m}$, however, a branched hole was 
formed because the laser reflected at a point near the surface. Appropriate control of laser fluence and sidewall tilt therefore enables curved hole formation. As shown in Fig. 3(b) and Fig. 5(a), the curve angle fluctuates. The fluctuation in curve angle is believed to be caused by the fluctuation of the sidewall shape where the laser beam reflected.

The branched hole was created by using the reflection of the tilted sidewall. The number of pulses, $P_{N}$, and the illuminated position is listed in Table 6 . First, eight cycles were executed with $P_{N}=100$ and $\Delta x_{N}=+2 \mu \mathrm{m}$, then the sample was returned to the position of $X_{8}=-2 \mu \mathrm{m}$. Then another seven cycles $(\mathrm{N}=9-15)$ were executed from the $X_{8}=$ $-2 \mu \mathrm{m}$ with $P_{N}=100$ and $\Delta x_{N}=-2 \mu \mathrm{m}$. This was followed by 4200 pulses which illuminated the specimen at $X_{16}=-16 \mu \mathrm{m}$. The sample was moved to $X_{17}=+16 \mu \mathrm{m}$ and another 4200 pulses illuminated the specimen. As a result, a branched hole was formed as shown in Fig. 10.

\section{Summary}

Curved hole drilling via the reflection of a laser beam at the bottom of the hole was reported. A curved hole was drilled (after a pilot hole was created) by shifting the laser illumination point. Proper pilot hole drilling conditions were investigated. As a result, a curved hole was drilled with an average curve angle of $\sim 3^{\circ}$ and the region of curvature was located at a depth of 400-600 $\mu \mathrm{m}$. A curved hole with a diameter of $<30 \mu \mathrm{m}$ was achieved. Formation of a branched hole was also demonstrated by using the reflection of the tilted sidewall.

The curved hole formation process was observed using a high speed camera. Laser illumination at the shifted position of the previously formed hole ablated the sidewall of the hole. The laser fluence was high enough to ablate the side wall when the ablated position was close to the hole entrance and therefore a straight hole was drilled along the beam axis. At the same time, the bottom of the hole was tilted and reflected the laser tangentially, 
enabling it to ablate the opposite side of the wall. When the ablated sidewall reached a

certain depth, ablation ceased because the laser energy fell below the ablation threshold.

However, ablation at the opposite side continued, and a curved hole was formed.

Appropriate laser fluence and sidewall tilt enabled curved hole formation. Glass was used

in this experiment to visualize the curved hole formation process. This technique, however,

is expected to be applicable to other materials, making this an important development in

micromachining.

\section{Acknowledgements}

The authors gratefully acknowledge the support of the Advanced Machining

Technology and Development Association (AMTDA), Amada Foundation and the Japan

Science and Technology Agency (JST) under the Development of Innovative Seeds,

Potentiality Verification Stage.

\section{Figure captions}

Table 1 Laser illuminated positions and number of pulses, $P_{N}=5000, \Delta x_{N}=2 \mu \mathrm{m}$.

Table 2 Laser illuminated positions and number of pulses, $N=11, P_{N}=40(N=1$ 10), $P_{11}=4600, \Delta x_{N}=2 \mu \mathrm{m}$.

Table 3 Laser illuminated positions and number of pulses, $N=11, P_{N}=100(N=$ 1-10), $P_{11}=4000, \Delta x_{N}=2 \mu \mathrm{m}$.

Table 4 Laser illuminated positions and number of pulses, $N=11, P_{N}=160(N=$ 1-10), $P_{11}=3400, \Delta x_{N}=2 \mu \mathrm{m}$.

Table 5 Laser illuminated positions and number of pulses, $N=17, P_{N}=100(N=1$ 16), $P_{17}=3400, \Delta x_{N}=2 \mu \mathrm{m}$.

Table 6 Laser illuminated positions and number of pulses for blanched hole formation.

Fig. 1 Transverse section of the drilled hole. $P_{N}: 5000$ pulses, $\Delta x_{N}: 2 \mu \mathrm{m}$.

Fig. 2 Transverse section of the drilled hole. (a) $N=11, P_{N}=40(N=1-10), P_{11}=$ 4600, $\Delta x_{N}=2 \mu \mathrm{m}$, (b) $N=11, P_{N}=100(N=1-10), P_{11}=4000, \Delta x_{N}=2 \mu \mathrm{m}$, (c) $N=11, P_{N}$ $=160(N=1-10), P_{11}=3400, \Delta x_{N}=2 \mu \mathrm{m},(\mathrm{d}) N=11, P_{N}=100(N=1-10), P_{11}=4000, \Delta x_{N}$ $=0 \mu \mathrm{m},(\mathrm{e})-(\mathrm{g})$ magnified image of (b) indicated by rectangular.

Fig. 3 (a) Explanation of the curved angle and depth measurement. Curved angle (b) and depth (c) with a different number of pulses in each cycle.

Fig. 4 Transverse section of the drilled hole. (a) $N=7, P_{N}=100(N=1-6), P_{7}=$ $4400, \Delta x_{N}=2 \mu \mathrm{m}$. (b) $N=17, P_{N}=100(N=1-16), P_{17}=3400, \Delta x_{N}=2 \mu \mathrm{m}$. 
Fig. 5 Curved angle (a) and depth (b) with different number of cycles.

Fig. 6 Transverse section of the drilled hole curved in different directions. $N=11$, $P_{N}=100(N=1-10), P_{11}=4000$, Left: $\Delta x_{N}=-2 \mu \mathrm{m}$, Center: $\Delta x_{N}=0 \mu \mathrm{m}$ Right: $\Delta x_{N}=+2$ $\mu \mathrm{m}$.

Fig. 7 Time-lapse photographs of the curved hole drilling (a), $N=11, P_{N}=100(N=$ $1-10), P_{11}=4000, \Delta x_{N}=2 \mu \mathrm{m}$. Left: whole image, right: magnified image at the hole bottom. Reconstructed hole profile (b), after 1200th pulse (red), 1300th pulse (blue) and 1400th pulse (black).

Fig. 8 Time-lapse photographs of the straight hole drilling, $N=11, P_{N}=100(N=$ $1-10), P_{11}=4000, \Delta x_{N}=0 \mu \mathrm{m}$.

Fig. 9 Illustration of the hole formation process.

Fig. 10 Transverse section of the branched hole. Illumination condition is shown in Table 6.

Movie 1 Curved hole drilling shown in Fig. 7 (a), each frame was recorded every 10 pulses and the movie was 10 frames per second. Hence 100 pulses were illuminated in 1 second.

\section{References}

[1] Ishida T, Takeuchi Y. Curved hole machining by self-movable mechanism with electrical discharge machining function: development of automatic discharge gap controller. J. Jpn. Soc. Precis. Eng. 1999;65:245-9.

[2] Sasahara H, Nagao S, Chino M. Electrochemical Curved hole machining with electrode posture control system(machine elements and manufacturing). Trans. Jpn. Soc. Mech. Eng. C. 2007;73:2619-24.

[3] Hidai H, Toriumi K, Matsusaka S, Chiba A, Morita N. Drilling holes by an emitting laser beam and liquid jet from a tip of a thin tube. J. Jpn. Soc. Abrasive Tech. 2013;57:65964.

[4] Hosono T, Kinbara M, Sakaki K. Laser drilling of single crystalline silicon in liquid etchant. J Jpn Soc. Abrasive Tech. 2012;56:190-5.

[5] Yamashita Y, Hosono T, Hidai H, Tokura H. Processing of silicon by direct irradiation of laser beam transmitted through optical fiber. J Jpn Soc Precis Eng. 2008;74:463-7.

[6] Hwang DJ, Choi TY, Grigoropoulos CP. Liquid-assisted femtosecond laser drilling of straight and three-dimensional microchannels in glass. Appl Phys A. 2004;79:605-12.

[7] Gattass RR, Mazur E. Femtosecond laser micromachining in transparent materials. Nature Photonics. 2008;2:219-25.

[8] Forsman AC, Banks PS, Perry MD, Campbell EM, Dodell AL, Armas MS. Doublepulse machining as a technique for the enhancement of material removal rates in laser machining of metals. J Appl Phys. 2005;98:033302.

[9] Tokarev VN, Lopez J, Lazare S. Modelling of high-aspect ratio microdrilling of polymers with UV laser ablation. Appl Surf Sci. 2000;168:75-8.

[10] Tokarev VN, Lopez J, Lazare S, Weisbuch F. High-aspect-ratio Microdrilling of Polymers with UV Laser Ablation: Experiment with Analytical Model. Appl Phys A. 2003;76:385-96.

[11] Ancona A, Roser F, Rademaker K, Limpert J, Nolte S, Tunnermann A. High Speed Laser Drilling of Metals Using a High Repetition Rate, High Average Power Ultrafast Fiber CPA System. Optics Express. 2008;16:8958-68.

[12] Döring S, Richter S, Heisler F, Ullsperger T, Tünnermann A, Nolte S. Influence of ambient pressure on the hole formation in laser deep drilling. Applied Physics A.

2013;112:623-9. 
[13] Kononenko TV, Konov VI, Garnov SV, Klimentov SM, Dausinger F. Dynamics of deep short pulse laser drilling: ablative stages and light propagation. Laser Phys.

2001;11:343-51.

[14] Döring S, Szilagyi J, Richter S, Zimmermann F, Richardson M, Tünnermann A, et al. Evolution of hole shape and size during short and ultrashort pulse laser deep drilling. Opt.

Express. 2012;20:27147-54.

[15] Xia B, Jiang L, Li X, Yan X, Lu Y. Mechanism and elimination of bending effect in femtosecond laser deep-hole drilling. Opt. Express. 2015;23:27853-64.[16] Hidai H, Itoh S, Tokura H. High-aspect-ratio microdrilling with UV laser ablation II.- Influence of beam parameters on hole profile-. J Jpn Soc Precis Eng. 2010;76:1266-70.

[17] Hidai H, Itoh S, Tokura H, Nagawasa S, Tachikawa S. High-aspect-ratio

Microdrilling with UV Laser Ablation I.-Drilling Holes with an Aspect-ratio of 190 in Borosilicate Glass- J Jpn Soc Precis Eng. 2010;76:1161-5.

[18] Hidai H, Matsusaka S, Chiba A, Morita N. Heat accumulation in microdrilled glass from ultraviolet laser ablation. Appl. Phys. A. 2015;120:357-67.

[19] Hidai H, Matsusaka S, Chiba A, Morita N. Modification of borosilicate glass induced by ultraviolet laser illumination. J. Mech. Lett. 2016: 2: 15-00686. 
Tables

Table 1

\begin{tabular}{r|r|r}
\hline $\begin{array}{l}\text { Number } \\
\text { of cycle } \\
\mathrm{N}\end{array}$ & $\begin{array}{l}\text { Position } \\
X_{N} \mu \mathrm{m}\end{array}$ & $\begin{array}{l}\text { Number } \\
\text { of pulse } \\
P_{N}\end{array}$ \\
\hline 1 & 0 & 5000 \\
2 & 2 & 5000 \\
3 & 4 & 5000 \\
4 & 6 & 5000 \\
$\ldots .$. & $\ldots .$. & $\ldots$ \\
\hline
\end{tabular}

Table 3

\begin{tabular}{r|r|r}
\hline $\begin{array}{l}\text { Number } \\
\text { of cycle }\end{array}$ & $\begin{array}{l}\text { Position } \\
X_{N} \mu \mathrm{m}\end{array}$ & $\begin{array}{l}\text { Number } \\
\text { of pulse } \\
P_{N}\end{array}$ \\
\hline 1 & 0 & 100 \\
2 & 2 & 100 \\
3 & 4 & 100 \\
$\ldots$. & $\ldots$. & $\ldots$ \\
9 & 16 & 100 \\
10 & 18 & 100 \\
11 & 20 & 4000 \\
\hline
\end{tabular}

Table 4

\begin{tabular}{r|r|r}
\hline $\begin{array}{l}\text { Number } \\
\text { of cycle } \\
\mathrm{N}\end{array}$ & $\begin{array}{l}\text { Position } \\
X_{N} \mu \mathrm{m}\end{array}$ & $\begin{array}{l}\text { Number } \\
\text { of pulse } \\
P_{N}\end{array}$ \\
\hline 1 & 0 & 40 \\
2 & 2 & 40 \\
3 & 4 & 40 \\
$\ldots$. & $\ldots$. & $\ldots$ \\
9 & 16 & 40 \\
10 & 18 & 40 \\
11 & 20 & 4600 \\
\hline
\end{tabular}

\begin{tabular}{r|l|r}
\multicolumn{3}{c}{ Table 4 } \\
\hline $\begin{array}{l}\text { Number } \\
\text { of cycle } \\
\mathrm{N}\end{array}$ & $\begin{array}{l}\text { Position } \\
X_{N} \mu \mathrm{m}\end{array}$ & $\begin{array}{l}\text { Number } \\
\text { of pulse } \\
P_{N}\end{array}$ \\
\hline 1 & 0 & 160 \\
2 & 2 & 160 \\
3 & 4 & 160 \\
$\ldots$. & $\ldots$. & $\ldots$ \\
9 & 16 & 160 \\
10 & 18 & 160 \\
11 & 20 & 3400 \\
\hline
\end{tabular}

Table 5

\begin{tabular}{r|r|r}
\hline $\begin{array}{l}\text { Number } \\
\text { of cycle } \\
\mathrm{N}\end{array}$ & $\begin{array}{l}\text { Position } \\
X_{N} \mu \mathrm{m}\end{array}$ & $\begin{array}{l}\text { Number } \\
\text { of pulse } \\
P_{N}\end{array}$ \\
\hline 1 & 0 & 100 \\
2 & 2 & 100 \\
3 & 4 & 100 \\
$\ldots$. & $\ldots$. & $\ldots$ \\
15 & 28 & 100 \\
16 & 30 & 100 \\
17 & 32 & 3400 \\
\hline
\end{tabular}

Table 6

\begin{tabular}{r|r|r}
\multicolumn{3}{|c}{ Table 6 } \\
$\begin{array}{l}\text { Number } \\
\text { of cycle }\end{array}$ & $\begin{array}{l}\text { Position } \\
X_{N} \mu \mathrm{m}\end{array}$ & $\begin{array}{l}\text { Number } \\
\text { of pulse } \\
P_{N}\end{array}$ \\
\hline 1 & 0 & 100 \\
2 & 2 & 100 \\
3 & 4 & 100 \\
$\ldots$. & $\ldots$. & $\ldots$ \\
7 & 12 & 100 \\
8 & 14 & 100 \\
9 & -2 & 100 \\
10 & -4 & 100 \\
$\ldots$. & $\ldots$. & $\ldots$ \\
14 & -12 & 100 \\
15 & -14 & 100 \\
16 & -16 & 4200 \\
17 & 16 & 4200 \\
\hline
\end{tabular}




\section{Figures}

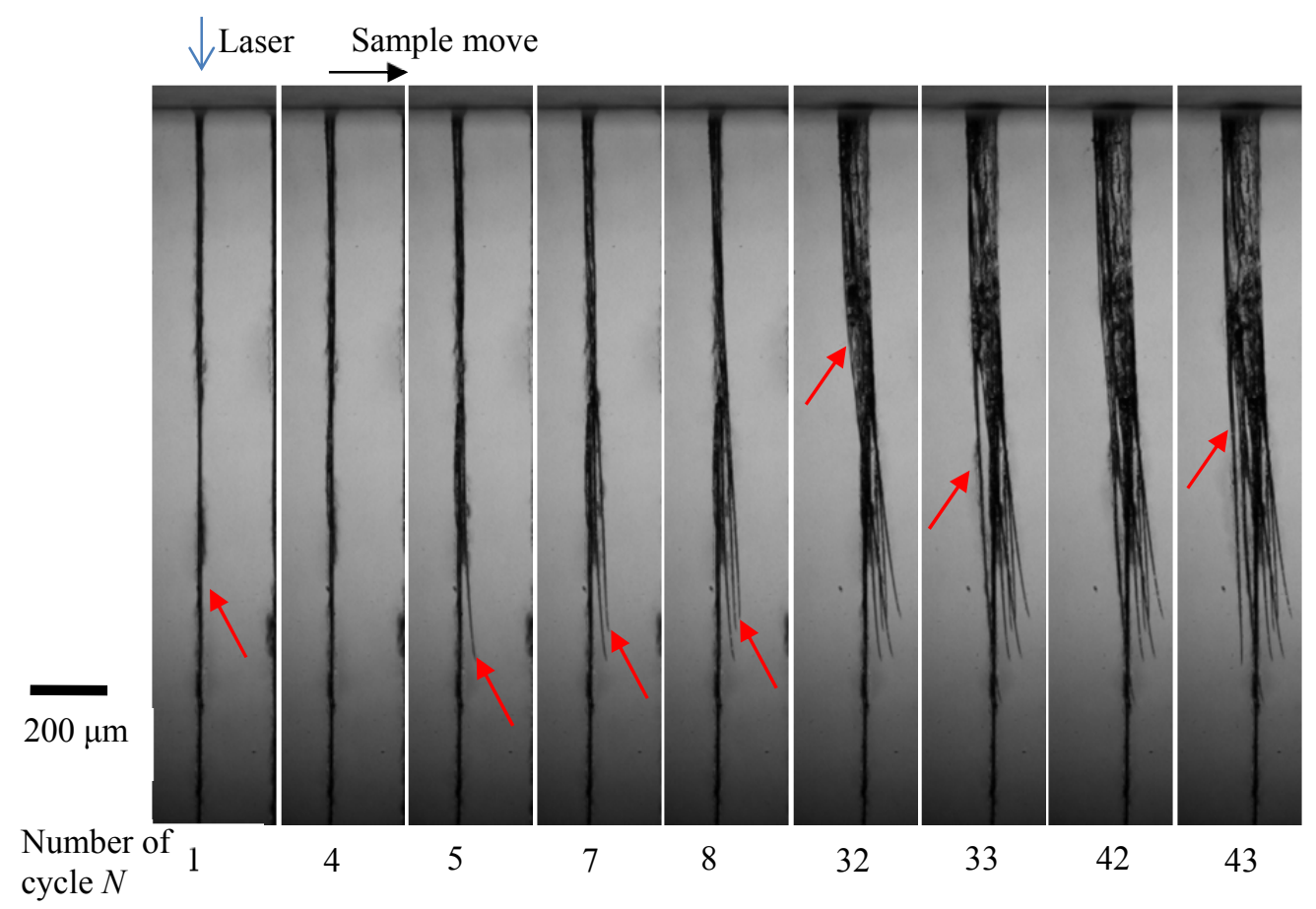

Fig. 1

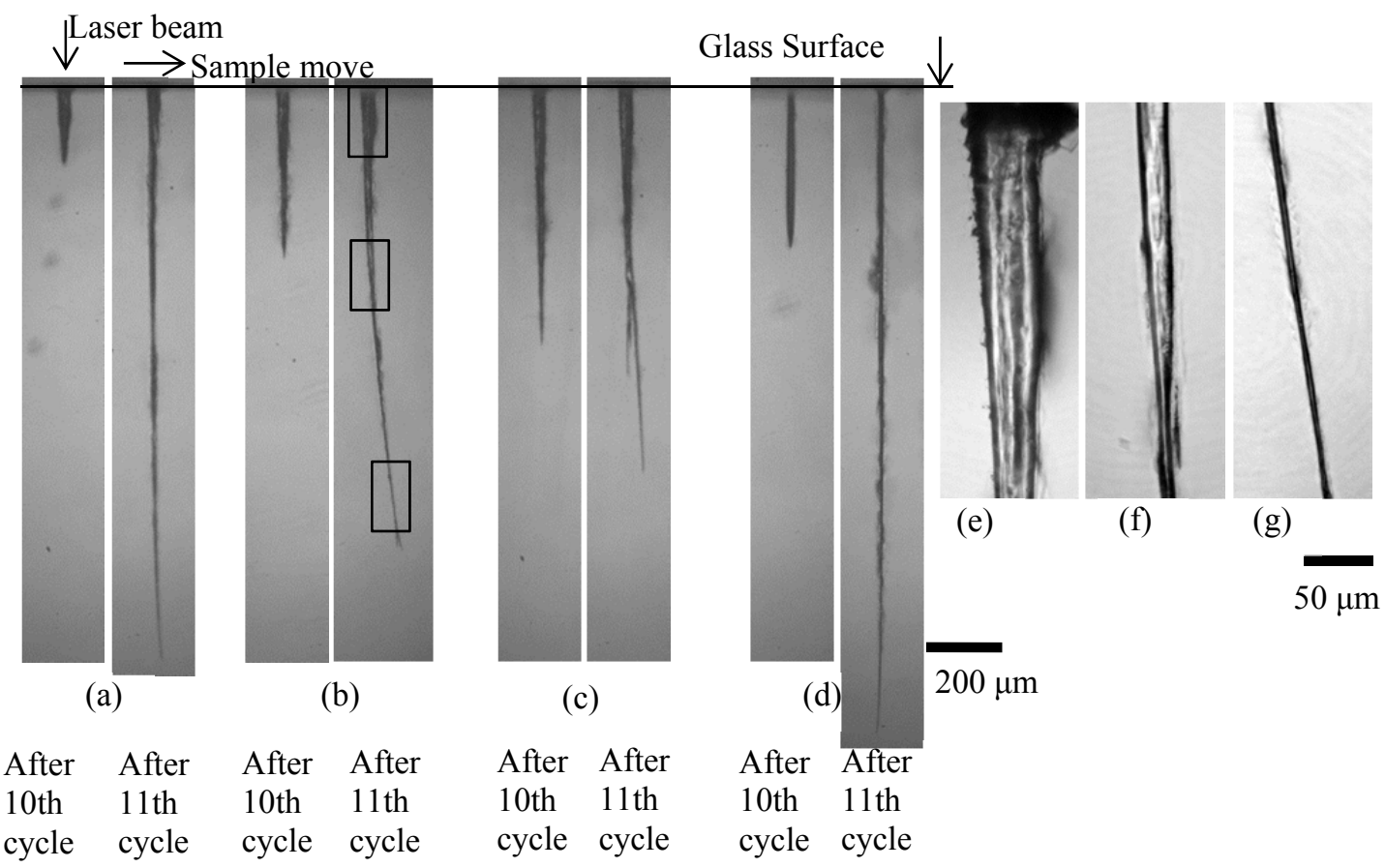

Fig. 2 

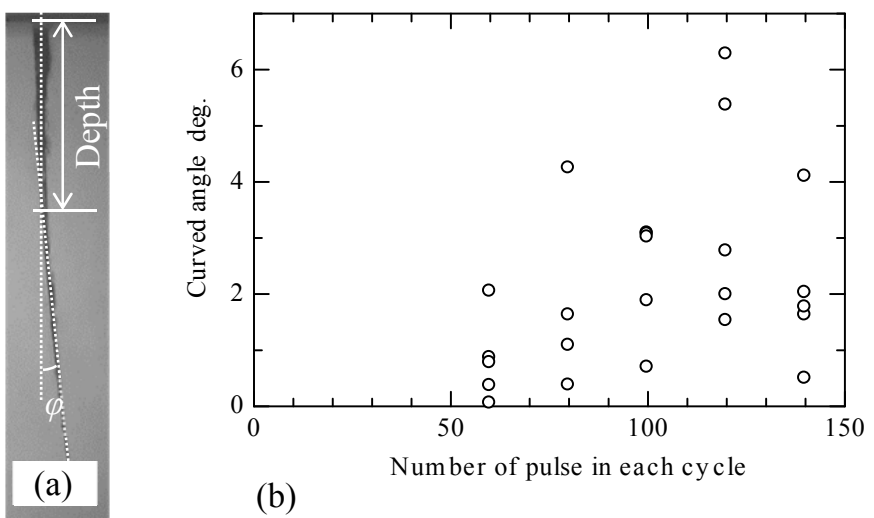

(b)

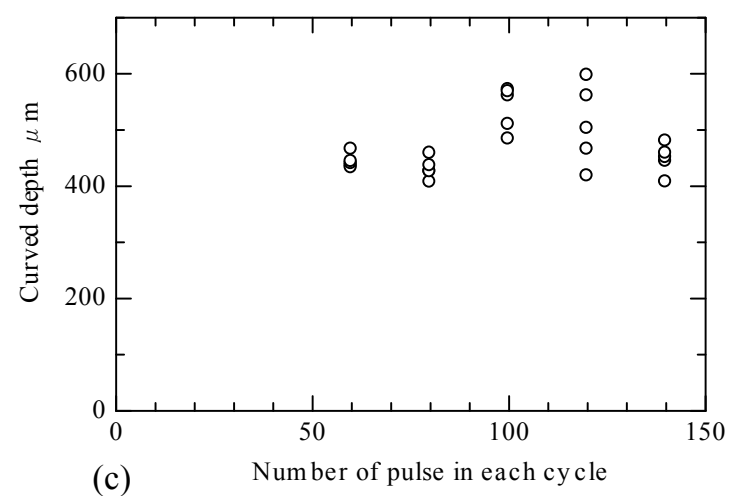

Fig. 3 


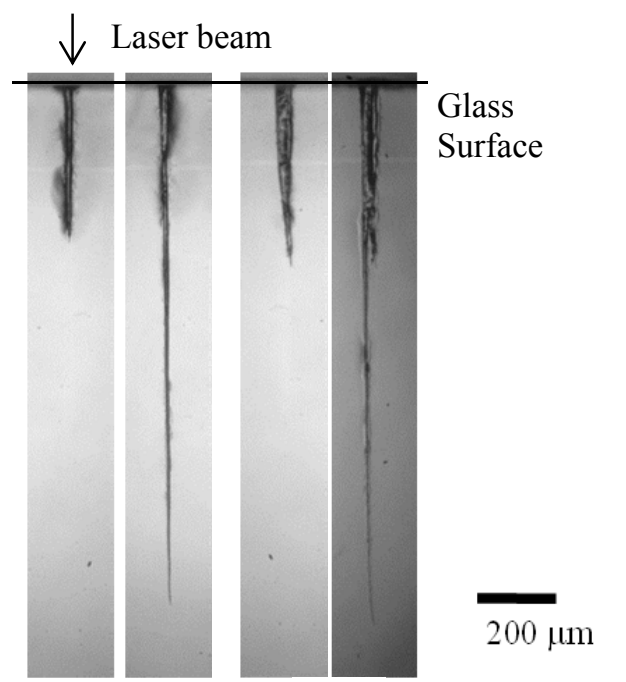

(a) (b)

After After After After 6th 7th 16th 17th

cycle cycle cycle cycle

Fig. 4 


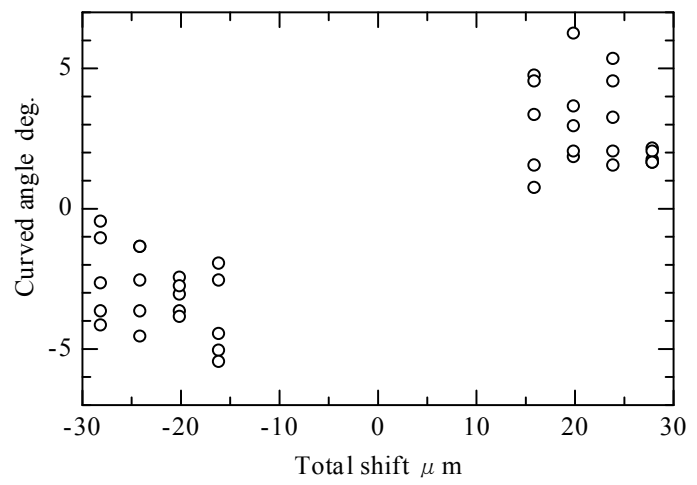

Fig. 5(a)

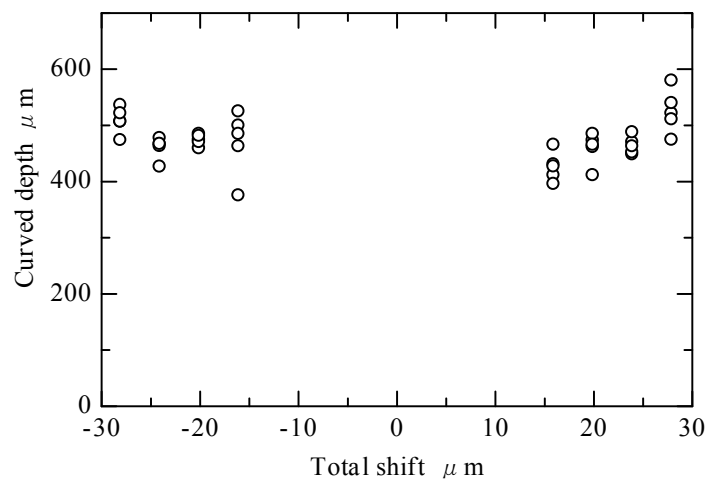

Fig. 5(b)

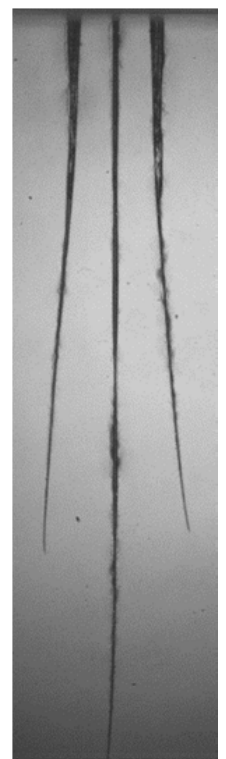

$200 \mu \mathrm{m}$

Fig. 6 

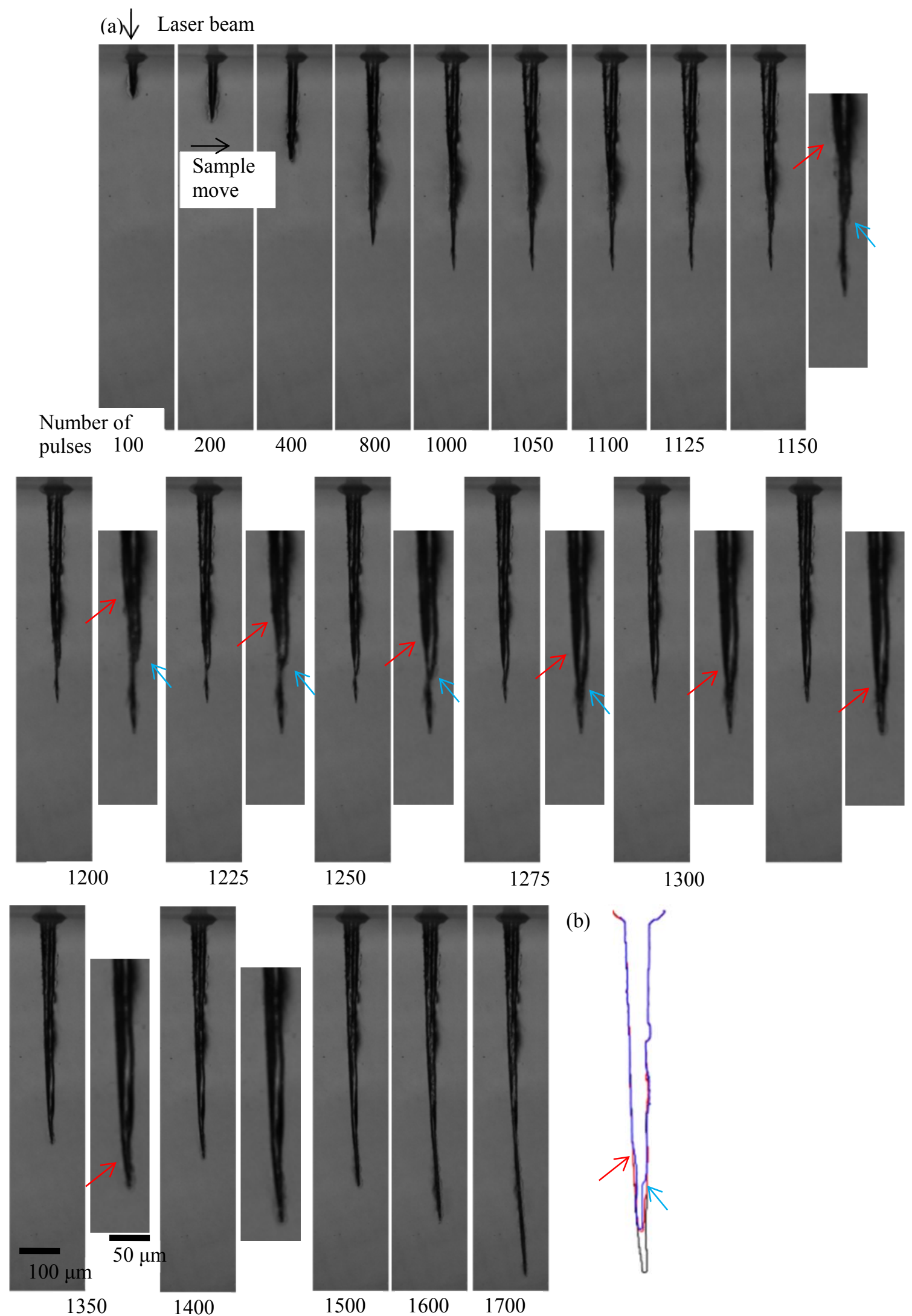

(b)

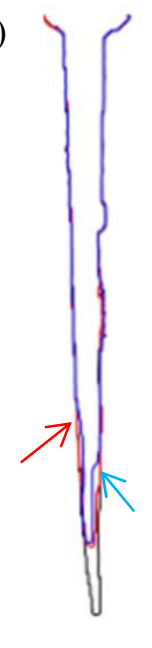

Fig. 7 


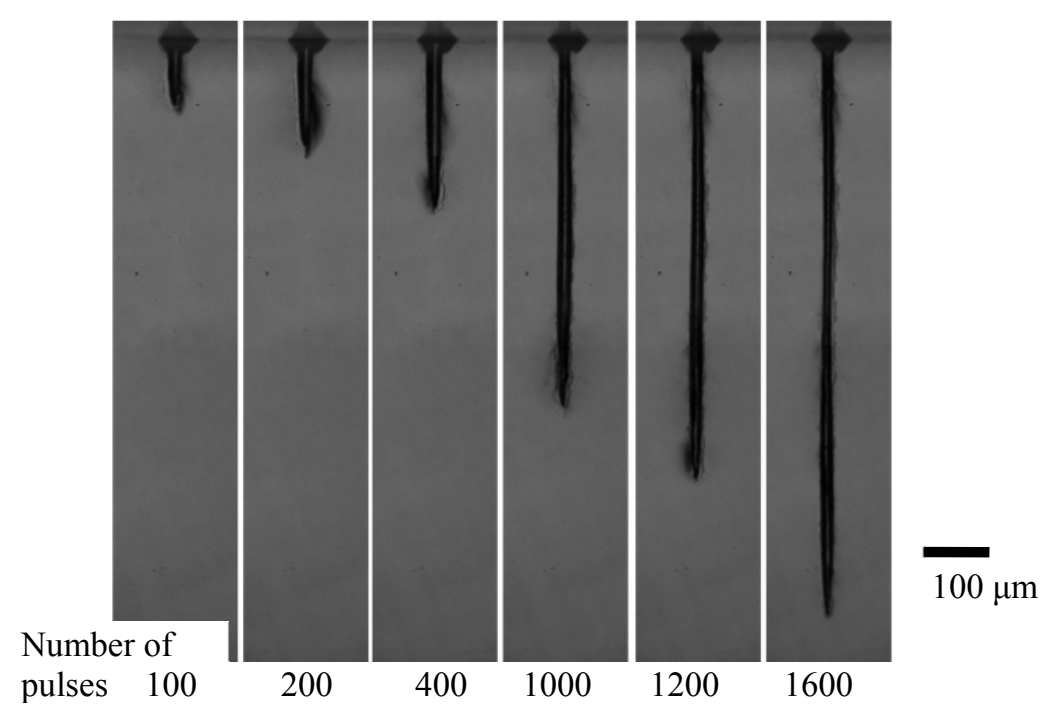

Fig. 8
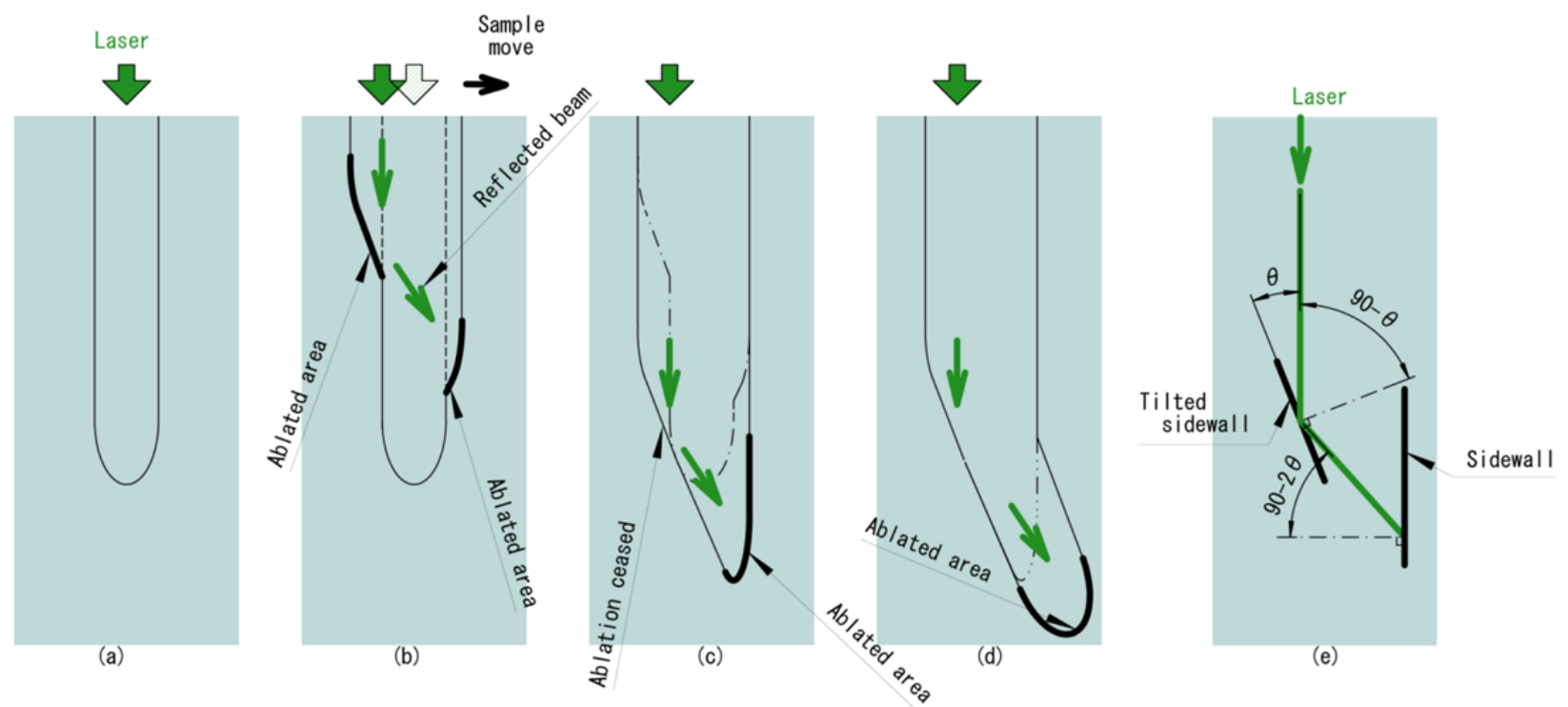

Fig. 9 


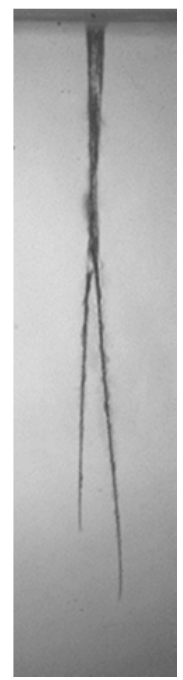

$200 \mu \mathrm{m}$

Fig. 10 